\title{
The Role of Emerging Technologies to Fight Against COVID-19 Pandemic: An Exploratory Review
}

\author{
Sanjoy Mondal ${ }^{1}$ [D $\cdot$ Priyanjana Mitra ${ }^{2}$
}

Received: 3 November 2021 / Accepted: 18 January 2022 / Published online: 3 February 2022

(c) Indian National Academy of Engineering 2022

\begin{abstract}
Since the end of the year 2019, the whole world is experiencing a global emergency due to the COVID-19 pandemic. The major sectors including industry, economics, education have been affected. Ongoing pandemics confined us to avoid mass gathering and rigorously maintain social distancing to mitigate the spreading of this infectious disease. In this situation emerging technologies including the internet of things (IoT), Artificial Intelligence (AI) is playing a very important role in various fields such as healthcare, economics, educational system, and others to monitoring or tackle the impact of COVID-19 pandemic. Several papers discussed the impact of IoT on the COVID-19 pandemic in various aspects. However, the challenges and designing issues towards the implementation of IoT-based monitoring systems are not deeply investigated. Alongside, the adaptation of IoT and other technologies in the post-covid situation is not addressed properly. Our review article provides an up to date extensive survey on how IoT-enabled technologies are helping to combat the pandemic and to manage industry, education, economic, and medical system. As result, the realization is that IoT and other associated technologies have a great impact on virus detection, tracking, and mitigate the spread. In the face of an expeditiously spreading pandemic, the associated designing issues of the IoT-based framework have been looked into as a part of this review. Alongside, this review highlights the major challenges like privacy, security scalability, etc. facing in using such technologies. Finally, we explore 'The New Normal' and the use of technologies to help in the post-pandemic era.
\end{abstract}

Keywords COVID-19 $\cdot$ IoT $\cdot$ Pandemic $\cdot$ IoMT $\cdot$ AI $\cdot$ Drone

\section{Introduction}

In December 2019, a novel strain of the coronavirus called SARS-CoV-2 has resulted in the outbreak of respiratory illness (known as COVID-19 acronym for Coronavirus Disease-2019) was first originated from Wuhan city in China's Hubei (Zhu et al. 2020; Backer et al. 2020). Like other influenza viruses, SARS-CoV-2 attacks the respiratory system which causes cough, fever, breathlessness, fatigue, etc. As because the exact source of the SARS-CoV-2 is unknown,

Sanjoy Mondal

sanjoymondal@soa.ac.in

1 Department of Computer Science and Information Technology, Institute of Technical Education and Research, Siksha 'O' Anusandhan (Deemed to be University), Bhubaneswar, Odisha, India

2 Department of Computer Science and Engineering, University of Calcutta, JD 2, Sector III, Salt Lake, Kolkata, West Bengal 700106, India based on the genome sequence it is determined to be a family member of the genera coronavirus (Cascella et al. 2020; Afelt et al. 2018). The virus has now spread to over 213 countries and territories across the globe and was declared as a pandemic by the World Health Organization (WHO) on 11 March 2020 (Gallagher et al. 2020). The world is now struggling to dominate the unprecedented spread of this infectious disease. To limit the damage of COVID-19 unprecedented public health actions are introduced, including social distancing, travel restrictions, and quarantine (Hao 2020; Haleem et al. 2020). To impose social distancing the 'lock-down' process is initiated all over the world by refraining from doing what is inherently human. This lock-down means confining millions of citizens to their homes, shutting down businesses, and ceasing almost all economic activity. Across all economic sectors, the workforce has reduced that causes less production. Schools and Colleges have been closed down, and needs for commodities and manufactured products have decreased (Whiteside 2020). Additionally, this pandemic has been left several hospitals in uncertainty, 
having reached their utmost capacity. Consequently, it leads to a global economy, health, and educational crisis. In this crucial situation, the top priority is to mitigate the transmission of diseases by maintaining social distancing precautions (Richardson 2020). To fight against the pandemic we need to handle this crisis strongly by resuming all systems but maintaining social distance. These challenges motivate the researchers of different fields to contribute to rebuilding our global system. Moreover, all the worldwide activities including business, education, health are becoming heavily dependent on technologies. As a consequence, various countries have started to adopt digital technologies including the Internet of Things (IoT), Machine Learning, Artificial Intelligence (Allam and Jones 2020), Fog/Edge Computing (Azimi et al. 2017; Jorge et al. 2020) and others to combat the global crisis and to minimize the risk of community transmission. The constant monitoring of the viral infection, quick diagnosis, treatment, observing the mass gathering and the containment zone, contact tracing, helping the medical doctors and nurses, enabling telemedicine (Marr 2020a), providing e-learning all of these requirements strongly relies on the availability of wireless communications (Saeed et al. 2020).

Internet of Things (IoT) is one such technology where physical objects are embedded with sensors, software, and network connectivity, and these objects can sense the outside world, processing, interpreting and forecasting realtime data, communicate, and exchange information with each other through a wireless network. This technology has already been implemented in the different domains including medical (IoMT), transportation, home appliances, and others (Ting et al. 2020; Javaid et al. 2020a). Amid the ongoing COVID-19 pandemic health care organizations, government, innovators are trying to take advantage of IoMT to reduce the burden of health care staff. Not only in the medical domain but applications of IoT are also numerous to continue virtual learning, to implement automated industry, assisting E-commerce. Moreover in the context of controlling the mass gathering and social distancing, tracking the spreading of virus, screening and surveillance, contact tracing the contributions of IoT are paramount (Javaid et al. 2020b; Singh et al. 2020b). Different countries have developed drones for crowd surveillance and screening the masses. Smart thermometer, IoT button, proximity devices, telemedicine (Nasajpour et al. 2020b) are introduced to handle the ongoing crisis, mitigate the spreading of the virus, and implement contactless services (Swayamsiddhaa and Mohanty 2020; Rahman et al. 2020). To successfully utilize all these supports of IoT technology-based applications high speed, high coverage, low latency enabled reliable 5G internet connection is a major issue (Qualcomm 2020). This paper aims to show how emerging technologies such as the internet of things (IoT), artificial intelligence (AI), drone and smartphone applications are assisting to combat the COVID-19 pandemic presented in Fig. 1. In addition to that how emerging technologies help monitor the crowd, contact tracing, social distance maintaining, supporting health care, supporting e-learning and e-commerce are presented in this review. Next, we discuss the challenges in using IoT in various aspects including security, privacy, misinformation. Finally, we discuss how IoT technology can be developed to make daily lifestyle easier in the post-pandemic situation.

Our contributions can be summarized in the following way:

1. We provide an up to date in depth survey on the role of IoT, mobile applications and other emerging technologies for detection and identification and to reduce the spreading of COVID-19.

2. We outline the impact of IoT in various sectors including medical system, educational systems, Automated industry, etc. Then, we address the associated implementation issues in each sector separately.

3. We highlight the major challenges including privacy, security, scalability, connectivity etc facing in using such technologies to combat COVID-19 pandemic.

4. We discuss how IoT and associated emerging technologies can be useful to deal with post covid situation in different aspects.

5. Finally, based on the assessment, we identify the future trends of IoT and emerging technologies to combating and managing a global pandemic such as COVID-19.

The rest of the paper is organized in the following manner. We discuss our research objective in the section "Research Objectives" and then our literature review and research methodology are presented in the section "Related Works" and "Methodology", respectively. A brief introduction of IoT and its role in various fields to fight against the

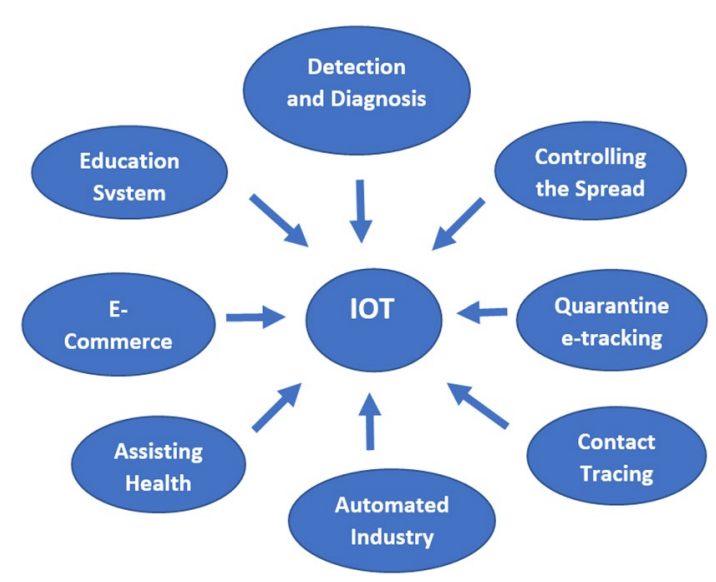

Fig. 1 Significant role IoT towards COVID-19 pandemic 
pandemic situation are explained in the section "Impact of IoT in Various Fields to Fight Against COVID-19 Pandemic" whereas the section "Emerging Technologies for Mitigating the COVID-19 Pandemic" explains the role of emerging technologies. The impact of mobile applications appears in the section "Mobile Applications for Mitigating the COVID-19 Pandemic" and in the section "Challenges in IoT-Based Infrastructure", we discuss the major challenges using IoT technology. Next, we highlight our research findings in the section "The New Normal-Post COVID-19" and discuss the role of IoT in the post-pandemic era in the section "Research Findings and Future Trends" followed by concluding remarks in the section "Conclusion".

\section{Research Objectives}

The COVID-19 pandemic impelled to break off almost all the sectors including business organization, healthcare, educational system and others from our usual life. In these unavoidable circumstances, it is a very challenging task to stop the spreading of coronavirus and to give the proper treatment and services to the infected people in a more productive, effective and impactful manner. The objective of this comprehensive review is to propose the various services in the different fields with the help of IoT and other associated technologies during these challenging COVID-19 situations. Another objective is to highlight the challenges and designing issues in developing IoT infrastructure to mitigate the coronavirus outbreak and investigate the changes that need to be adapted in post-COVID situation (i.e. 'The new normal'). A great challenging task is to identify the contaminated geographical area by detecting the infected people and maintain the social distances to stop the spreading. These issues can be reconciled more effectively and conveniently with the help of IoT and few other emerging technologies. It also helps to serve the remote locations where the medical or any other services cannot be supplied otherwise in timely and efficiently. In addition to that, IoT infrastructure can resolve the issues in the educational system, automated industry, E-commerce and others with the help of various unfold technologies and mobile applications. Therefore, it is pivotal to identify the techniques and methodologies that can resolve various issues related to the global COVID-19 pandemic. Concomitantly, the challenges and design issues, to achieve these effectiveness, also need to be addressed. We present our research plan of this comprehensive review in Fig. 2.

\section{Related Works}

To date several papers discussed the impact of the COVID19 pandemic. In Chakraborty and Maity (2020) the impact of COVID-19 in connection to our society and global environment is considered and as well as the authors have tried to point out the preventive route to reduce the risk factors. As the preventive strategies they mainly specified forestation to reduce pollution, controlling human population, restricting mass gathering, developing safe and stable COVID-19 vaccine etc. This paper did not highlight the usefulness of IoT as the controlling and preventing strategy of coronavirus. Oyeniyi et al. (2020) focused on the application of IoT to combat COVID-19 pandemic. However,here the utilization of IoT was highlighted only in the medical domain. They proposed an IoT based process that enables treatment of infected person remotely. According to this process, data of infected patients can be collected remotely by smartphone based application, then analyzed the collected data and based on the result of analysis health workers will start the

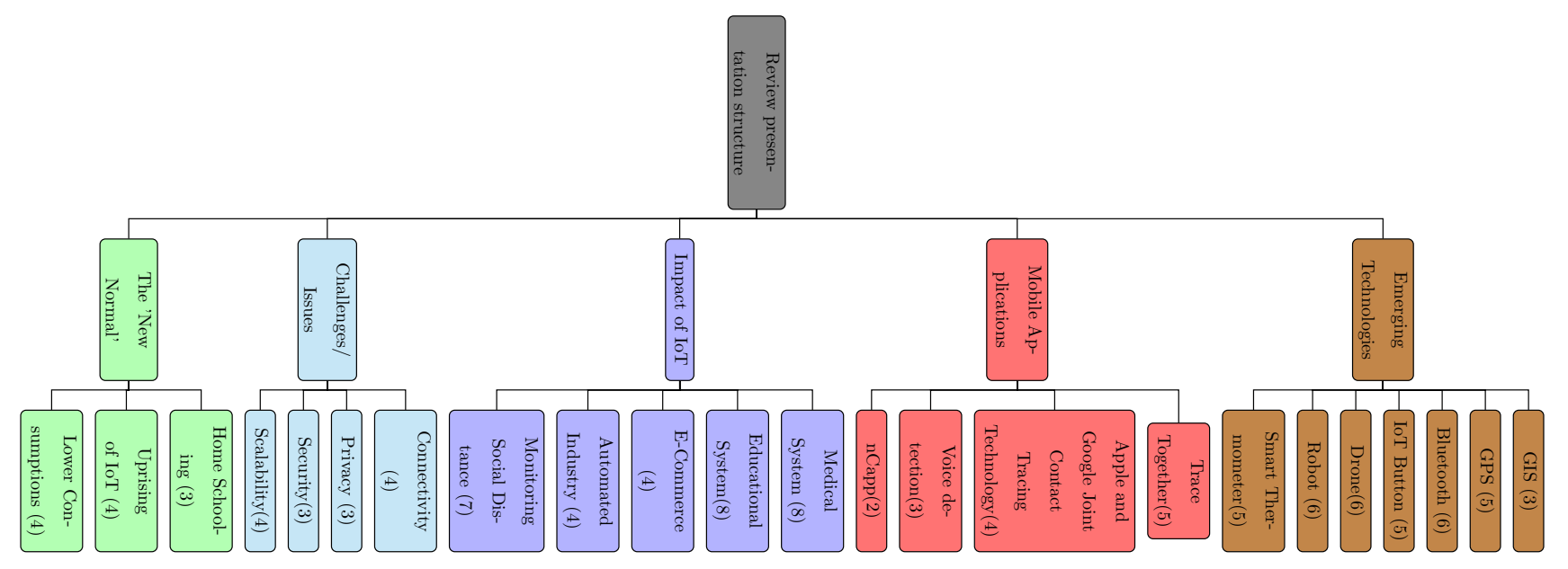

Fig. 2 Plan of systematic literature review (SLR), number indicates the research articles selected in respected category 
treatment of infected patient. In Nasajpour et al. (2020a), Nasajpour et al. surveys the importance of IoT in COVID19 pandemic situation in different manner. It highlights the application of IoT in different phases of COVID-19 diseases like the early diagnosis phase, quarantine time phase and after recovery phase. Mondal et al. (2021) presents a survey on the role of the internet of things to fight against coronavirus and proposed a IoT-based infection detection framework that is effective for early detection of COVID-19 infected or suspected people. Smart Thermostat, Intelligent cap, Smart Spec these type of reliable and cost effective devices can be used to monitor an infected person by controlling spreading of virus. Author Kumar et al. (2021) proposed a smart healthcare infrastructure by utilizing IoT which is required to mitigate the spreading of virus and to reduce the extreme pressure of our medical staff. Like application of IoT helps to track live location of a quarantine patient, remote health monitoring and storing patient data, checking availability of ambulance for COVID-19 patient etc. In this critical situation, when we all are forced to strictly follow all the covid protocols, Malliga et al. (2021) explores, how we can use our emerging technologies in our daily life maintaining social distancing. In Bassam et al. (2021) authors proposed a three-layer IoT infrastructure for remote health monitoring system where the first layer is wearable IoT layer that senses different parameters of COVID-19 patient like temperature, oxygen saturation, heart rate etc. The second layer is the cloud layer that receives the sensed data and stores it as patient record and the last layer is the web fronted layer which mainly analyzed the patient record received from the cloud layer and alerts the authority time to time. Singh et al. (2020a) explores how IoT can help to an orthopedic patient to his treatment and to make his life convenient during this pandemic whenever he is living in a remote location where medical facilities can not reach timely. Apart of the health care domain Business organizations are also facing huge challenges in this pandemic situation. This situation forces entire industries to rethink and retransform their global supply chain model. Since 2020 several researchers have been started to give their attention in the supply chain area to tackle the disruption. Chowdhury et al. (2021) reviewed the effectiveness of supply chain disciplines in the COVID-19 pandemic and the possible future scope on it. In Shahed et al. (2021) a three-layer optimization model is developed to help in redesigning the inventory policy to maximize the profit and reduce the disruption of the supply chain in this pandemic situation. de Sousa Jabbour et al. (2020) addressed the role of a supply chain manager in this COVID-19 situation to build a smarter and more resilient supply chain management (SCM) system. The supply chain managers have to reassess the structure of the business in terms of location, production capacity, flow of material management. Based on this assessment they have to reconstruct the new structure of the supply chain which will be easy to handle in this pandemic situation. A methodology is proposed in Karmaker et al. (2021) based on Pareto analysis, Fuzzy theory, Total interpretive structural modeling (TISM), Matriced Impacts Cruoses Multiplication Applique a un Classement (MICMAC) to improve the supply chain sustainability in the context of COVID-19. The impact of coronavirus is also present in the food and beverages industries. Chowdhury et al. (2020) analyzed the impacts of COVID-19 in the food and beverage company.The authors mainly investigated the short-term and medium to long term impacts of COVID-19 in the food and beverage industry and proposed different strategies that can help the sector to recover quickly from these difficulties. Like First Expiry First Out, Product rotation, reducing operational expenses, restructuring the supply chain may minimize losses of food companies.

To the best of our knowledge, there are a few papers that discussed the impact of the COVID-19 pandemic situation on all the sectors such as healthcare, education, industry, E-commerce, etc. Alongside, the challenges and designing issues towards the implementation of such an IoT-based framework is still ignored. This review article clearly illustrates the effect of this global pandemic in various domains such as healthcare, education system, E-commerce, Business organizations and others. To mitigate this, how various IoTbased tools and technologies are effective is described in this article. This paper also discussed the challenges towards the IoT in terms of connectivity, security, privacy and scalability. In addition, briefly discussed how these tools and technologies can help us in our new normal life.

\section{Methodology}

A large number of interconnected heterogeneous devices can be connected to form a network to fight against global pandemics such as COVID-19. Automated tracking and alert system are possible to integrate and collect the relevant health and personal data (e.g. location information) of the suspected persons from various locations. In this section, we discuss an IoT-based complete framework that is possible to design with the help of existing IoT ontologies. This IoTbased framework may be utilized for real-time surveillance and identification of COVID-19 infections alongside reducing the spreading of the illnesses. The framework consisting of the following five components: Data collecting and transferring, Data analytics center, Healthcare/Quarantine center, Healthcare system/Professional, and Cloud infrastructure. A key phase of this model is that all of its constituents are linked together via a cloud infrastructure. PaaS is an abbreviation for Platform as a Service. Figure 3 shows the architecture of the IoT-based monitoring system. 


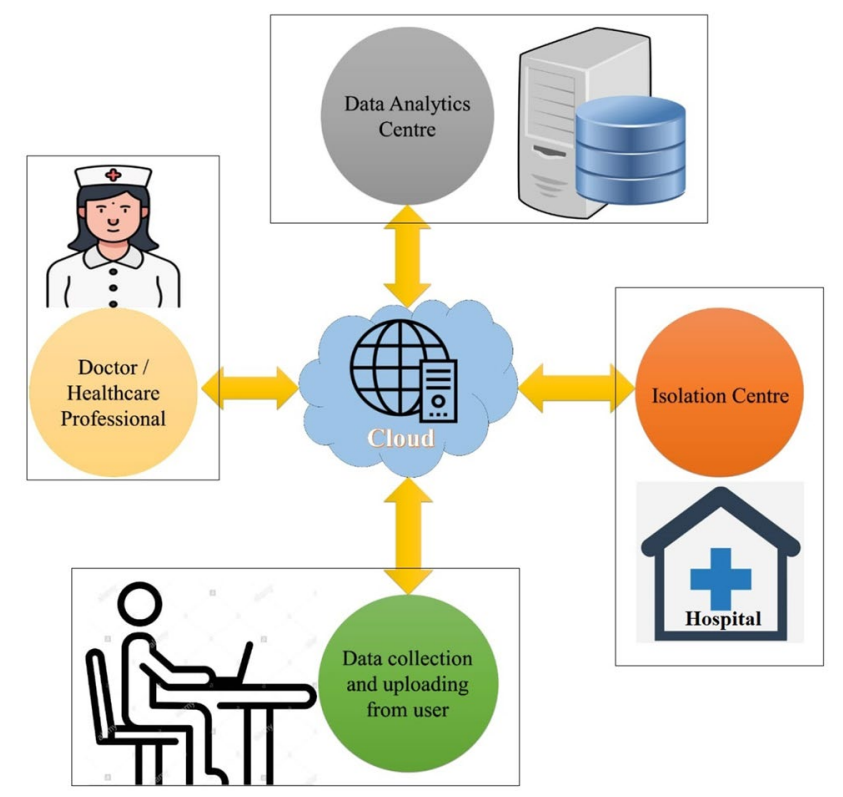

Fig. 3 IoT-based framework for COVID-19 infection detection and monitoring

\section{Data Collection and Transferring from Users}

A variety of wearable gadgets are available for collecting real-time ailment data from users. The involvement of various wearable gadgets and their uses are described in this literature. Numerous bio-medical sensors can be installed for recognizing COVID-19 related complaints. To stop the spreading of coronavirus, location information of infected patients can be collected to calculate the social distances among the people. Smart thermometers may be used to measure a person's real-time body temperature. Even though the user who is in transit, their body temperature may be monitored (using a smart helmet). Other important user data, such as trip records and interaction records, can be gathered via several mobile applications.

\section{Data Analytics Centre}

Data analytics elements evaluate the data and execute various machine learning (ML), Deep learning (DL) algorithms until it has been gathered and sent to cloud servers. The analytics center creates several statistical data analytics models to be used on real-world data gathered and uploaded by the users. The model that was created can be used to identify users' data in real-time. Using different monitored ML techniques, the ML model can also recognize the patient's states (such as critical, non-critical, and so on). By calculating social distances, using various mobile apps or other alert systems, alert messages can be sent to people to maintain social distances. The analytics center changes the system throughout the term based on real-time data and provides pertinent information to users/healthcare professionals as needed.

\section{Hospital and Quarantine Centre}

Since all of the modules are linked via the cloud, this section gathers user details as well as patient conditions from the data analytics center. Depending upon that patients' condition, if a patient needs to travel to the quarantine or isolation center, the quarantine center communicates with the client to offer a quarantine center, relying on the database record supplied by the users devices. Throughout patients' quarantine, the quarantine center communicates with the data analytics center to provide patients' updates. It also communicates with doctors/health care professionals to provide the patients' condition and follow the necessary instructions/ advices .

\section{Healthcare System/Professional}

All individuals, either isolated or taken to the hospital, are being monitored by the healthcare center/doctors. If any unexpected indications are discovered in patients, they notify the data analytics center, which updates the data collection and also the machine learning models, allowing ML equipments to re-learn. Clinicians also contact directly with patients whenever feasible to reinvestigate medical tests or provide other medical services and guidance. Employing IoT technology, a smart healthcare system may be developed in which consumers do not need to travel anyplace for the initial detection of COVID-19 indications. They may publish from any location using their smartphones.

\section{Cloud Infrastructure (PaaS)}

The PaaS cloud platform creates a forum for connecting the entire system over the online network. It enables customers to transmit real-time complaint information to the cloud server from any location and at any time. It keeps track of the patient's personal health information and interacts with health professionals as well as provides isolation facilities. It also offers the storage capabilities that this system requires.

\section{Impact of loT in Various Fields to Fight Against COVID-19 Pandemic}

The internet of things (IoT) refers to a network of interconnected physical objects embedded with sensors, software and circuits for continuous sensing and gathering data from the outside world (Yusuf et al. 2019). The gathered data are processed to extract the necessary information to bring 
about the change in the environment. IoT is a scalable and automated solution that has shown explosive growth in a wide range of applications including health care, Agriculture, Business Industry, Education, E-commerce, Transport, Economy to make the system much smarter (Qi et al. 2017; Reddy and Krishnamohan 2017; Pratama et al. 2017). The whole world is going through a significant complication of the COVID-19 pandemic and facing a serious challenge to tackle the COVID-19 pandemic (Chamola et al. 2020; Dudhe et al. 2017). The number of affected persons is increasing drastically day by day, and there is a huge need for a well adequate and organized system to arrest the destructive disease (WHO 2020b). In this situation, it is a vital task is to descry and fend off the spreading of Coronavirus and to help the practitioners to offer the proper treatment to the patients. In this context, the contribution of IoT is undeniable. This review article scrutinizes and presents the current research activities that have been effectuated with the help of IoT along with other emerging technologies.IoT application already has been deployed for monitoring the social distancing (Tang et al. 2016) and quarantine patients, tracking the virus, sanitizing the containment zone, supporting e-learning facility (Bahuguna et al. 2018), providing contact-less treatment in health care domain (Hu et al. 2013; Goswami et al. 2019; Sachin et al. 2019). This technology can collect realtime data and other necessary information effectively and by supporting a high-speed network can send it to the authority for taking appropriate steps as per necessity (Kumari et al. 2020). The various ponderous role played by IoT to combat the COVID-19 pandemic can be summarized as: (refer to Fig. 1)

- Diagnosis and collection of infected patient's data timely and in efficient manner.

- Detection and controlling the outspread of Coronavirus infection.

- Tracking and quarantine the infected persons.

- Contact tracing of coronavirus infected patients.

- Help the medical, health practitioners.

- Dispense of medical equipments, medicines, food and other necessary items.

- Remote monitoring of the quarantined patients.

\section{Role of IoT in Medical System}

Currently how to fight against the COVID-19 pandemic is a hot-spot research topic in the medical domain. All the health-care officials are working incessantly round the clock to protect citizens from infection, to save the people who are already infected and to provide the best facilities in their own way. Since the entire community is affected, it is very difficult to handle this situation with these few individuals. In this scenario, IoT amalgamated with artificial intelligence
(AI) and other emerging technologies can be a promising solution to combat with COVID-19 pandemic. Moreover in the medical domain internet of things (IoT) along with few advanced technologies forms a more specific technological system (called the internet of medical things (IoMT)) have already made a valuable contribution to handle the damage due to COVID-19, to minimize the burden of overworked hospital staff accordingly has lessened the risk of spreading the virus from infected person to health-care personnel. Now in the USA healthcare experts are using video conferencing, live Facebook webinars for consulting with several people and sharing their advices (see Fig. 4). The smart thermometer developed by Kinsa is becoming very popular for screening people by avoiding direct contact with the patient (Young and McMahon 2020). Camera-embedded facial scanners can be used to screen and analyze hospital visitor's facial attributes and thermal scan to detect a visitor's fever conditions (Schmitt 2020). Recently, a non-contact infrared sensor system has developed to distinguish individuals with fever even in masses. Use of $5 \mathrm{G}$ technology can facilitate the use of medical robots to deliver drag, screen the temperature, heartbeat, respiratory rate of an infected patient, disinfect the hospital, and taking adequate actions as per doctor's advice that minimizing the risk of exposure of medical staff to the virus (Saeed et al. 2020). In addition to that drones can be used for rapid delivery of medicine and supplies from one medical center to another or from one medical center to the home of COVID-19 patient. The Octopus National health Care management platform and Mobile app offers a personal monitoring app for quarantine patients. The patient needs to download the mobile app and to register their details. The response center monitors the person and receives a notification if a person is found to change his geolocation. Furthermore, the app allows the person to send updates about any signs of disease or changes of his condition to the response center. It allows us to have a video chat, and to receive notifications from the national health response center (Octopus

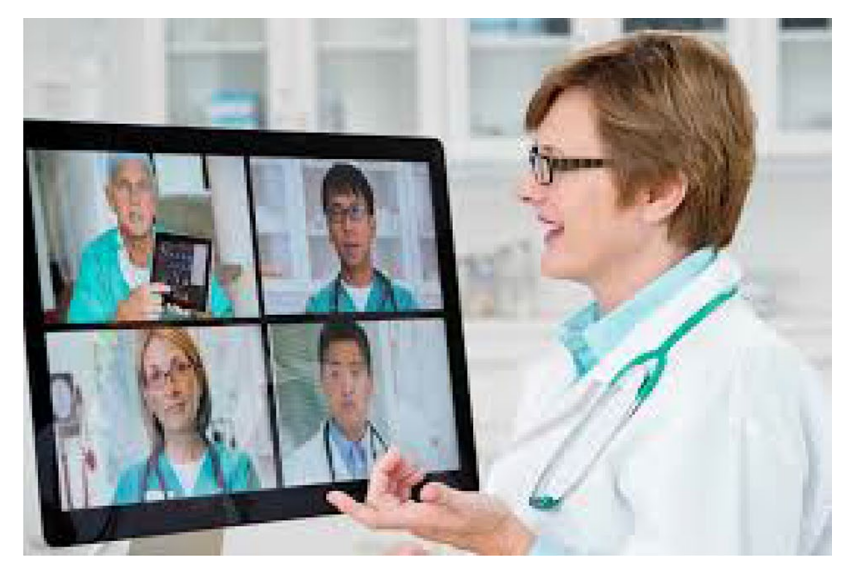

Fig. 4 Doctors consulting through virtual meetings APPs in hospitals 
2020). In addition to that, the IoT wearable device helps to monitor the quarantined person's temperature. Even different mobile applications are developed for providing essential health services to the people during this pandemic situation (Kaur 2020). These apps alert people by giving information on how many COVID-19 positive cases are likely in a radius of $500 \mathrm{~m}, 1 \mathrm{~km}, 2 \mathrm{~km}, 5 \mathrm{~km}$, and $10 \mathrm{~km}$ from the user, which helps to identify COVID-19 symptoms and its risk profile.

The IoT applications in healthcare have also met several challenges on the way.

- One of the most significant challenges is data security and privacy.IoT-enabled mobile devices capture data in real-time, but most of them lack adherence to data protocols and standards. There is significant ambiguity regarding data ownership and regulation. Hence, the data stored within IoT enabled devices are prone to data thefts and it makes the data more susceptible to cyber-criminals that can hack into the system to compromise personal health information.

- Smart healthcare demands a massive storage structure because having thousands of devices in a single healthcare facility and a thousand more sending information from remote locations will generate a huge amount of real-time data. Hence it makes the storage requirement is huge. If we can use AI-driven algorithms and cloud can help to organize these data but to build this matured infrastructure is time-consuming.

- The integration of multiple types of devices also causes obstruction in the implementation of IoT in the healthcare sector. The reason behind this obstruction is that device manufacturers haven't reached a consensus regarding communication protocol and standards. In such a situation, there is no synchronous protocol that could be followed for data aggregation. This non-uniformity slows down the process and reduces the scope of scalability of IoT in healthcare.

- Costs are one of the greater challenges when planning to consider IoT app development for healthcare mobility solutions. However, the costs are completely worth it if the IoT implementation is one that solves a genuine problem.

\section{Role of IoT in Educational System}

The outbreak of the COVID-19 pandemic also has created immediate and unprecedented challenges in the field of education. As of 31 st March, 185 countries around the globe have implemented or announced the closure of schools and universities as a precautionary measure to reduce the spread of the virus. In this time of crisis, digital learning has emerged as an indispensable resource for education. Digital technology is providing all sorts of remote learning opportunities for students across the globe and enabling teachers to create intriguing (virtual) experiences (Ethirajulu 2020). All around the world, schools are leveraging existing platforms from the likes of Google classroom, Microsoft Education, and conferencing apps like Zoom (refer to Fig. 5). Furthermore, besides virtual education, conferences, and meeting across the world are becoming online (Suroor and Khan 2017). Online conferences/meetings can be more satisfying with the support of Virtual Reality (VR) (Keyes 2019). This year IEEE conference on VR and 3D user interface were held on Mozilla's VR platform Hubs to motivate the people for "forgetting video conferencing and hosting next meeting to VR" and the response of this conference is overwhelmingly (Ackerman 2017). Recently another concept has developed ' $\mathrm{vFabLab}$ ' is an online-based virtual environment, which is designed to help training on semiconductor device fabrication processes and associated equipment. Moreover, the researchers are thinking of consolidating the exiting 'Learning Management System' (LMS) with an IoT smart watch (Heikkila 2017). The benefit of this integration is while people in their travel they can still access the LMS via smartwatch device and can remind, share, and upload any important material, data, and information in the system that can be readily accessed by the students from any learning platform (Froilan 2020).

Indeed digital learning can be a superior option than the conventional offline classes. The requirements for digital learning are digital devices and a high-speed network connection. In this area, $5 \mathrm{G}$ technology can play an important role. 5G facilitates telecommuting and virtual meetings in a different way to incorporate remote education as a part of everyday life (Chamola et al. 2020). However, it cannot be ignored that a vast portion of the world has limited or no internet access at all. They may risk falling further behind. Education systems have to ensure that these efforts do not further amplify the existing inequalities in access to learning and must pay heed to the quality of education and equal

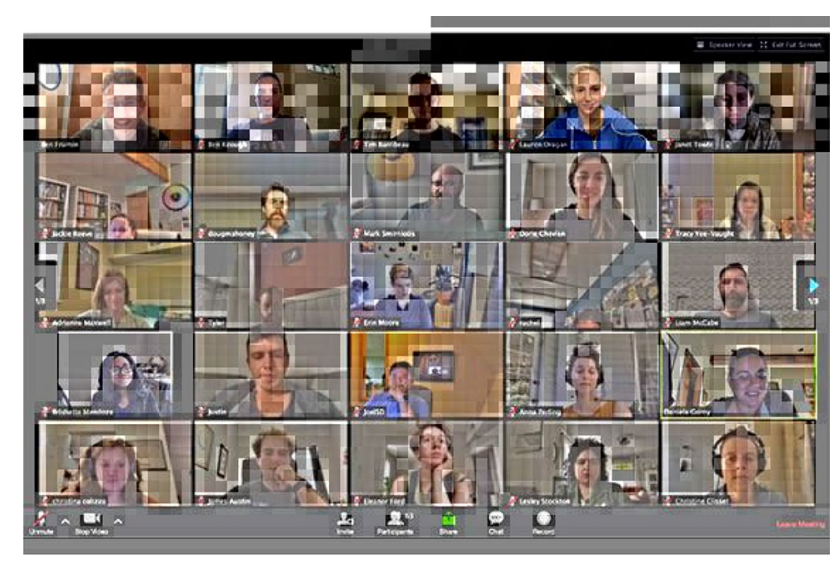

Fig. 5 Virtual conference room 
access to resources for all. Though digital technology holds great promise to provide access to high-quality learning, it may change the landscape of school education forever.

\section{Role of loT in E-commerce}

In fact during this pandemic e-commerce is appearing as a critical pillar to prevent the downfall of the global economy (Goodman 2020; Atkeson 2020). To implement effectively the social distancing measures to reduce the further spread of COVID-19, several governments around the world have encouraged online purchasing instead of physical shopping and consumers have adapted their shopping patterns and behaviors to minimize risks of getting infected (World Bank 2020). As person-to-person delivery is not virus-proof, many delivery companies and restaurants all over the world are launching a contact-less delivery service where goods are picked up and dropped at the designated location by Robot deliveries. Moreover, cash might carry the virus so contactless digital payments, either in the form of cards or e-wallets are the suggested payment method to avoid the spread of COVID-19. Digital payments enable people to make online purchases and payments of goods, services and even utility payments as well as to receive stimulus funds faster (Amazon 2020).

However, most retailers lack the infrastructure and network components that huge volumes of IoT data require. In order for merchants to digitize their retail stores, they would need to have a robust network, cloud solutions and end-user solutions such as barcode scanners, tablets, and more. All of those things would require considerable investment. Here also integration of $5 \mathrm{G}$ technology with IoT, AI, blockchain and AR/VR will upgrade the E-commerce (Kshetri 2018).

\section{Role of IoT in Automated Industry}

During the COVID-19 crisis, the government and different industries around the world are facing a critical dilemma to balance the people's safety with an economic livelihood. In this field also remote services and digital solutions are making a major contribution to keep people safe, production running and critical supply chains and economic livelihood preserved (Sisinni et al. 2018). Moreover, Industrial applications have been faster in the adoption of IoT which is called the Industrial Internet of Thing (IIoT) (Khan et al. 2019). It offers self-organizing, remote monitoring, enabling machine to machine talking along with prognostic maintenance, attaining near to zero error with less manual intervention. The blockchain of IoT also calls for a distributed and secure exchange of data captured through these sensors or devices. The interconnection of blockchain technology and IoT (Panarello et al. 2018) have been in the scene since 2015, to solve critical IoT challenges related to security and data privacy (Hassan et al. 2019).

Now to implement this concept of IIoT we need stable, reliable, uninterrupted, high speed, low latency connectivity to provide continuous monitoring and automation. All these metrics are properties of 5G technology. Therefore to successfully implement the concept of IIoT, 5G technology can obtain paramount importance. Besides its lack of clear business objectives, improper organizational alignment, lack of IoT experts, IoT security threats are some common challenges in the case of the implementation of IIoT. An autonomous machine can be hacked with malware. To overcome all of these challenges we require running cyber security risk assessment at periodical intervals during the lifecycle of the IIoT device.

\section{IoT to Monitoring the Spread and Social Distance}

Across the globe, countries have implemented different control measures to protect their human civilization. According to WHO, restricted crowd and maintaining social distancing are two objectives of the public health care system (WHO 2020a). Both outdoor and indoor monitoring is required to measure the spreading of the virus. In this section, we discuss different applications of IoT in both the outdoor and indoor environment for tracking the spreading of this infectious disease. In most cases, the infected person has some travel history. So it is extremely important to track the locations and movement of the people and test their health in time. A smartphone application can easily track the location of registered individuals by using the Global positioning system tracker (GPS) allowing authorities to notify about individual location (Nosta 2020). Another Concern in this pandemic situation is contact tracing of the infected patient. According to a study by Massachusetts Institute of Technology (MIT), by superimposing geographic information systems (GIS) on IoT mobile data, it can assist epidemiologists in identifying people who have encountered the infected patients (Choudhary 2020). The technology can also assist in monitoring patients who are at high-risk and can provide useful data to the health-care workforce to take adequate action. In this context, the contact tracing app developed by Google and Apple is very useful to identify who is in close proximity with a confirmed COVID-19 infected individual. Besides, this app can provide details of COVID-19 cases with some useful information like how can mitigate the chance of further spreading and what to do if the patient deteriorates. In Fig. 6 the red marked box indicating the violating of safe social distance while the green marked box indicates safe distancing. The information of the persons continuously sent to the authoring body to take actions in real-time if there is any violation of social distancing is detected. This can help in minimizing the spread 


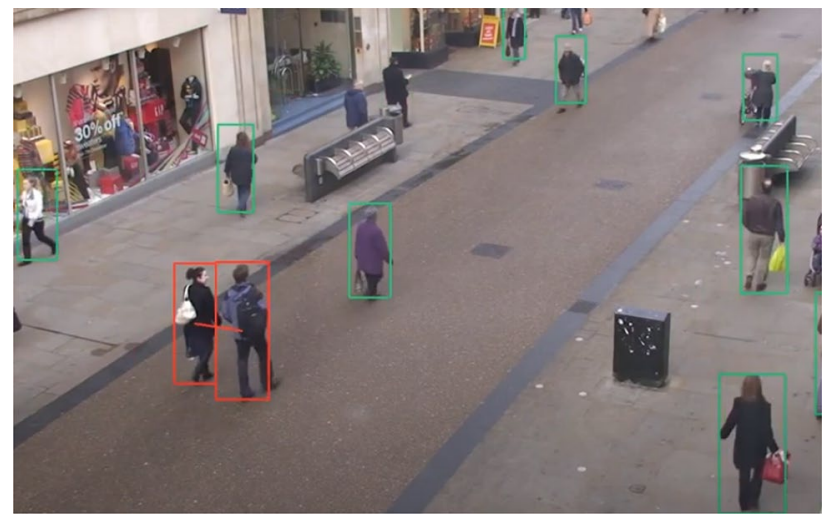

Fig. 6 Social distance detector App

of coronavirus. Various countries have are already deploying the 'Pandemic Drones', with an automated voice message to remind people to maintain their social distance and to avoid mass gathering (see in Fig. 11). This Drone also has high tech sensor that helps to monitor the temperature, heart and respiratory rate of people and can single out people sneezing, coughing in a public place. Once the drone collects the critical information, it sends the information to the authorities immediately for taking necessary actions in time. Furthermore, this drone can be used to enter infected regions and spray disinfectants. This can reduce the chance of further spreading of infection and minimize the exposure of frontline workers. Pandemic drones with 5G connectivity can take a supreme role in such a situation for its high transmission speed and low latency.

Satellite communications also play a significant role in monitoring, modeling and responding to the COVID-19 spread. Such outbreaks tend to be place-based: they emerge and cluster in certain places and certain contexts and are transmitted along certain pathways. As such, geospatial data is becoming an essential tool for infectious disease modeling. Also, satellite imagery can be used to monitor places where it is more likely to emerge or to look for the prevalence of certain risk factors. Monitoring Indoor Environment is more challenging due to the inadequacy of the GPS signal. There are several smart home IoT devices like smart video door phones, smart vigilant cameras, smart locks, smart lights, smart TVs and smart air conditioners (ACS). All these devices by being run by contactless voice assistants such as Google Assistant, Alexa, and Apple Siri so apart from adding to the convenience of the homeowners and the residents of a premise, can also prevent users from coming into direct physical contact with the delivery persons, milkman, newspaper delivery boy, online delivery agent and the postman. In such a way these smart gadgets help to prevent exposure to the virus through physical contact. In this context another new solution is a build-up for 'Proximity Trace'

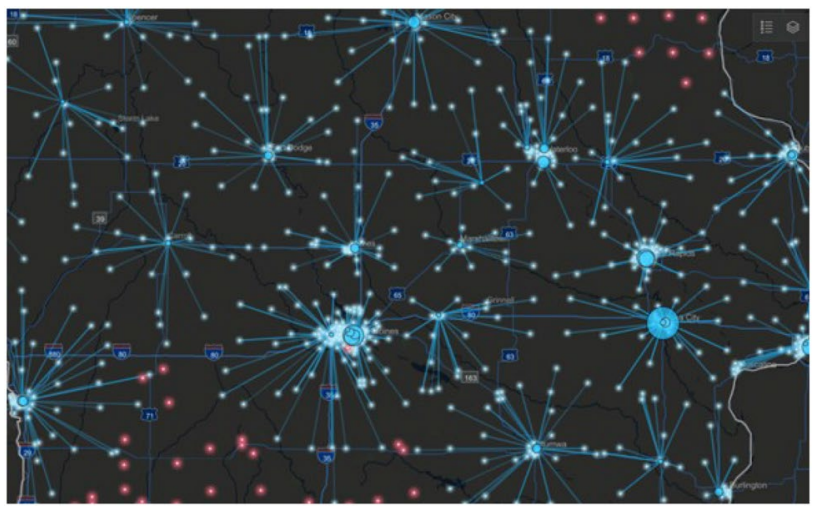

Fig. 7 GIS technology helps to identify a high risk infected zone

is 'Trace Tag' (Trace 2020). It can help to keep people safer by maintaining social distances in the workplace and gives support to organizations' strategies for getting back to work, during the time of COVID-19.

\section{Emerging Technologies for Mitigating the COVID-19 Pandemic}

Some emerging technologies including Geographic Information System (GIS), Global Positioning System (GPS), Bluetooth, etc. have widely been using to detecting, and helping the infected people (Khaddar and Boulmalf 2017) in various way. A large array of IoT wearable technologies includes smart thermometers, intelligent cap, smart glasses, and trace proximity that have the great applications to mittigating the COVID-19 pandemic and are discussed al follows:

\section{Geographic Information System}

To identify the geography of the contaminated area is very crucial in detecting, understanding and responding to any infectious diseases outbreak especially in pandemic such as COVID-19 disease. In this context, Geographic Information System (GIS) helps epidemiologists to identify the origin of the outbreak against several parameters such as demographics, environment, and past occurrences by using spatial analytics, mapping, and location intelligence (Lokhman et al. 2012) (see Fig. 7). Furthermore, it supports governments to identify high-risk zone and arrange the health-care facilities for the hazardous zone (Xiaosheng and Yuxuan 2009). An international GIS software provider Environment Systems Research Institute (Esri) working with various organizations as well as government agencies to help them leverage GIS technology to make decisions, plan and communicate various measures to control the spread of pandemic (Decker 2020). 


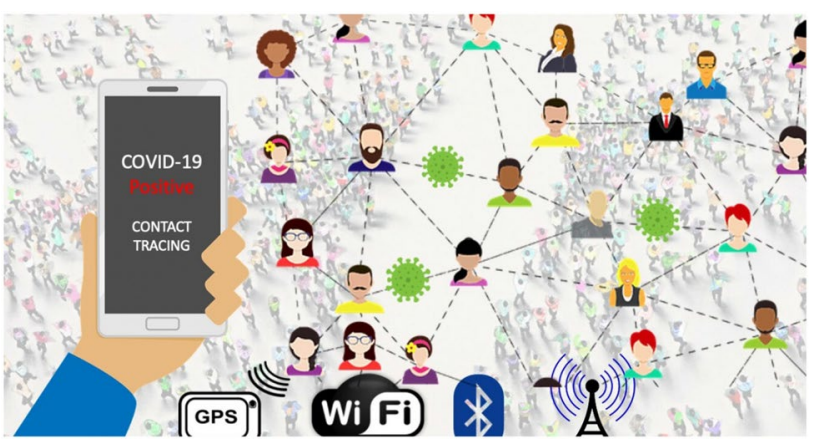

Fig. 8 GPS and bluetooth help for maintaining social distances

\section{Global Positioning System}

Global positioning system (GPS) technology is playing an important role in the time of COVID-19 pandemic (Nosta 2020). It is very useful for monitoring social engagement and distancing in time of locked down and quarantine period (see Fig. 8). GPS derived location data facilitates to map and analyze the movement of individuals and a large number of peoples. Simple GPS tracking applications could be downloaded into phones, and local authorities could analyze data to be confirmed that residents are going only to essential businesses and not traveling outside of designated areas (Tahmid and Dong 2020). It can be implemented with the help of local authority and the emergency service providers like medicine shop, healthcare center, fire detection etc. All the emergency service provider centers for a particular zone, with the help of local authority, can be registered through GPS tracking apps and for that particular zone only towards these service locations can be allowed to move for the people. If all the services are registered through the GPS tracking apps, only the person travelling towards those emergency services can be considered that she is going towards emergency services. Though, through this mechanism cent percent identification is not possible, however it can prevent the unnecessary travelling to some extent. Further, public health officials could use it to enforce the quarantines of infected individuals or their contacts.

\section{Bluetooth}

In this pandemic situation, Bluetooth is the most useful technology for proximity tracking (Blog 2020). Since the infection rate of COVID-19 is extremely high, the contact tracing technology must be accurate and perform a quick search. Bluetooth is the most suitable technology as it allows tracers to identify contacts within 2-3 m. Bluetooth contact tracing apps mainly determine proximity between two people by computing distance between their devices with the help of the Received Signal Strength Indicator (RSSI)
(Bluetooth 2020). To trace all the people who had interacted with COVID-19 infected patients the Bluetooth connection history of the patient device can be very useful (see Fig. 8).

\section{Smart Thermometer}

Eight years ago a US health care technology company name Kinsa had launched a smart thermometer to screen the people of common flu (Chamola et al. 2020; Young and McMahon 2020). In this pandemic situation when the infection is spreading rapidly and maintaining social distance is one of the objectives to control the spreading of the virus, a smart thermometer is playing a significant role by screening fever of infected patient and saving the front-line workers from this infectious disease (refer to Fig. 9). This thermometer is connected to a mobile application, which enables people to transmit the reading of the thermometer to the Company and then Kinsa assimilates the data to make a daily chart to identify in which area of US has a high possibility of being contaminated by COVID-19 (Charters 2020).

\section{IoT Button}

It is a small wireless-enabled programmable device that triggers specific actions by pressing only one button (Nasajpour et al. 2020b) refer to Fig. 10. This button has already proved its potentiality in case of hospital management like it allows providing real-time notification in restroom cleanliness, critical supply restocking, etc. Now in this pandemic situation IoT button is giving support to all health workers to manage better and faster diagnoses, identify a high-risk patient and notify the management and the patient party about any emergency and infected area (Chai et al. 2018).
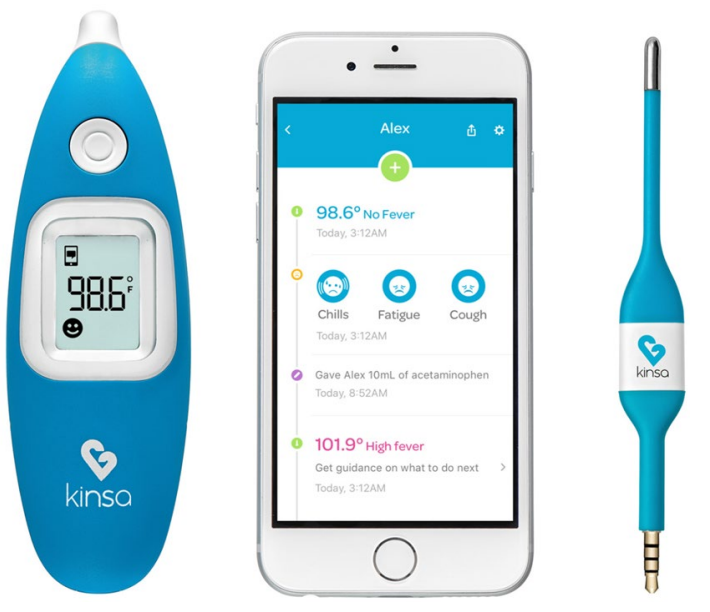

Fig. 9 Smart thermometer 


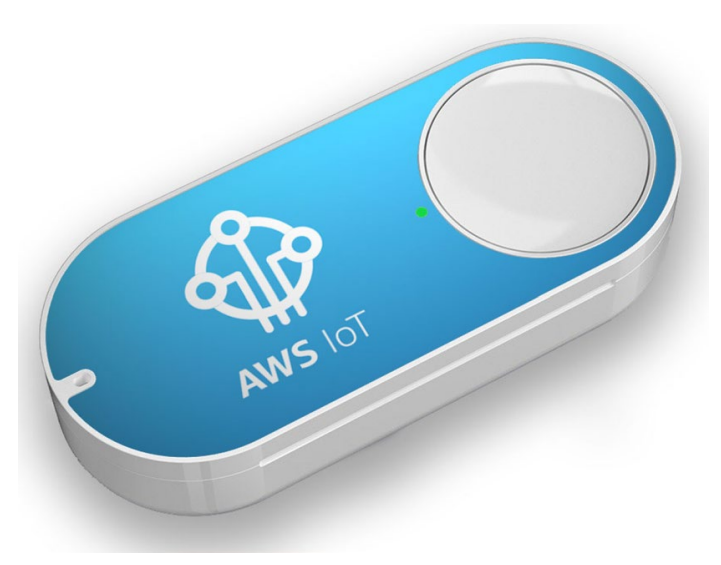

Fig. 10 AWS IoT-Button

\section{Drone}

In this ongoing war against invisible enemy COVID-19, drones play a key role by helping the government and people in several ways to prevent the further spread of the Coronavirus outbreak (Abdulrazaq et al. 2020). Around the globe all authorities and local municipalities are using drones for various purposes starting from monitor people's movement to thermal image scanning, break social gathering (refer to Fig. 11). In this time of crisis, the introduction of drones is reducing the risk of getting infected to frontline social workers like police officials and other staff since it enables monitoring a vast range of areas without physical engagement.
China and many European countries are also using drones for broadcast messages and information about lockdown measures like make social distancing, wear a mask, take necessary precautions to maintain hygiene, and prevent the spreading of the virus, especially in a rural area that lacks open communication channels for health (Sharma 2020). Drones also can be used for spraying disinfectants in potentially affected areas (Shaw and Vimalkumar 2020). In the medical area, drones are being used for delivering medical supplies and testing samples from hospital to hospital or from hospital to laboratory in the fastest and safest way (Zema et al. 2016).

\section{Robot}

With the changing of time, just like other technologies, robots are also playing an important role in the fight against diseases like COVID-19 (Thomas 2020). In the case of an outbreak, the robotic technology can play a crucial role in not just assisting the patients but also keeping the doctor and health-care staff safe (Tavakoli et al. 2020). Doctors are taking the help of a robot to treat a patient without coming in contact with the infected patient directly. A large number of hospitals in the country have been using robots to disinfect the contaminated zones with ultraviolet ray (Marr 2020b). Foodservice in another area where the use of robots is likely to increase because of safety measurements. Different companies like Amazon, Walmart are using Robots for sorting, shipping, and packing (see Fig. 12).
Fig. 11 Different kind of drones to manage the impact of COVID-19

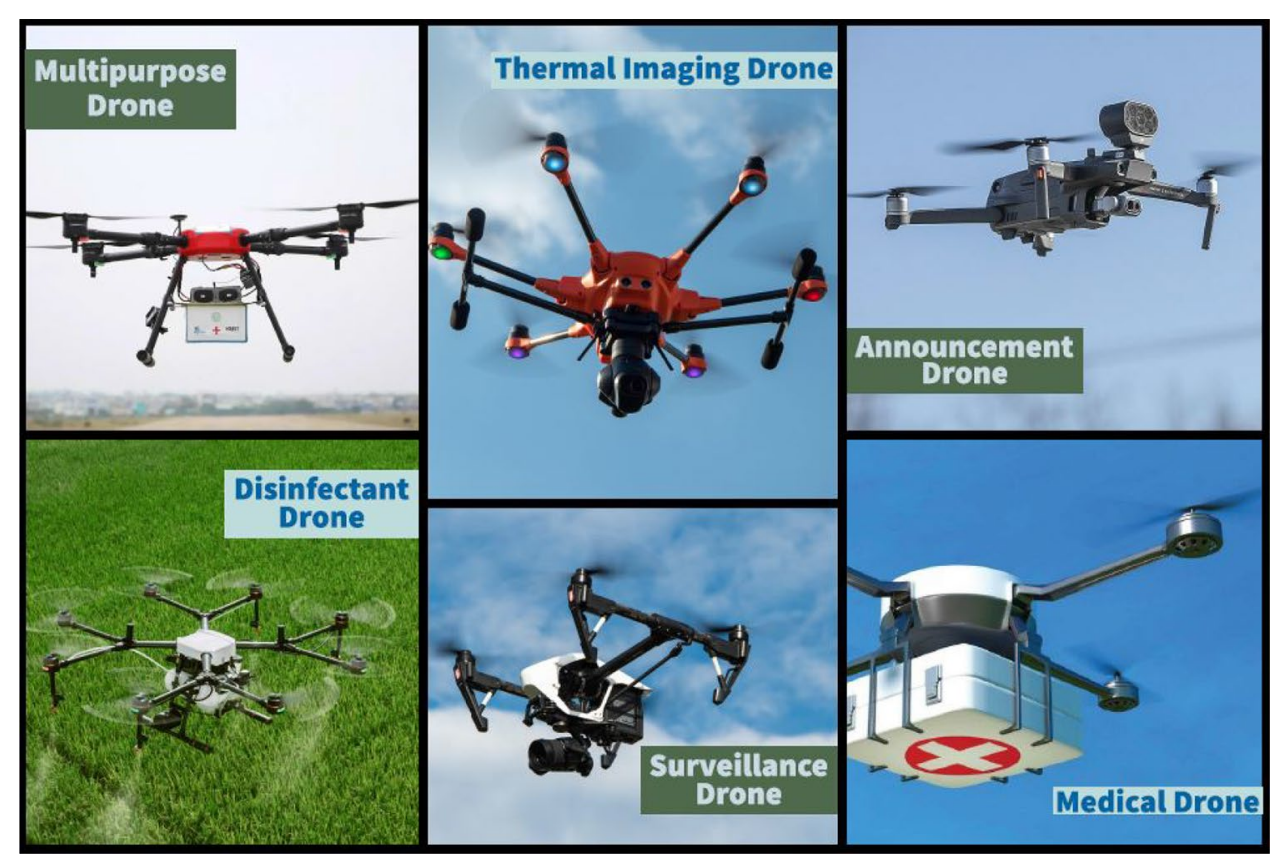




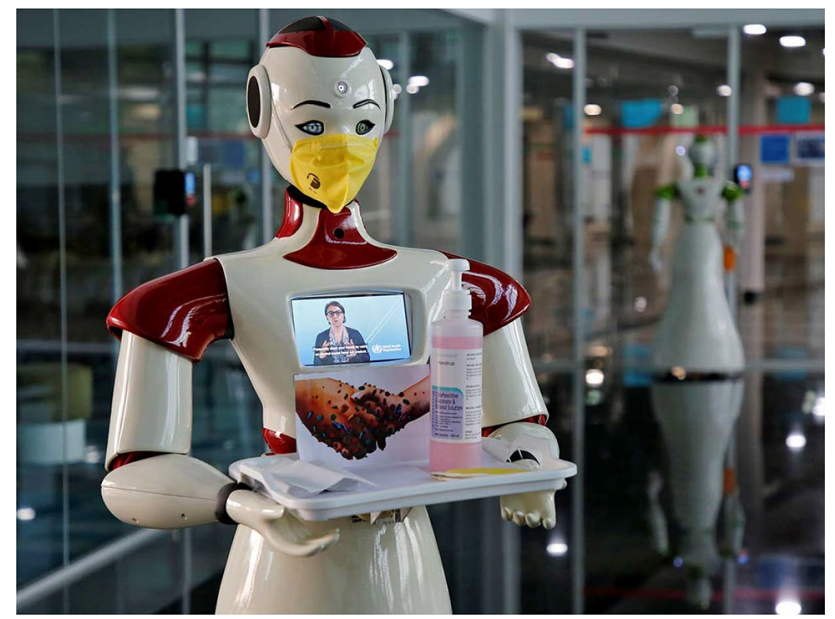

Fig. 12 Robot as an essential workers in COVID-19

\section{Mobile Applications for Mitigating the COVID-19 Pandemic}

Mobile applications software package is optimized to do constrained obligations inside a mobile phone inclusive of a smartphone. Although 3.5 billion operational smart mobile devices exist throughout 2020, such IoT-based smart mobile devices can become very productive in a number of contexts, including, telemedicine, healthcare, manufacturing and agricultural production. During the COVID-19 pandemic, mobile applications with IoT capabilities are widely used. These applications use information such as the Global Positioning System (GPS) and Geographic Information System (GIS) for tracking of the infected people in a population (Khaddar and Boulmalf 2017). The use of the Internet of Medical Things (IoMT) to integrate mobile applications will help individuals to provide correct treatments while at residence. This also makes it easier for health care providers and also government agencies to monitor the spread disease among patients. Individuals may transfer their medical details to the IoT cloud network and receive primary healthcare advice online (Uraguchi et al. 2019; Bai et al. 2020). Individuals can be healed at residence by using this technology without extending the pollution. It charges less than a formal nomination in clinics and enables authorities to implement greater measures in the future to handle this kind of disease outbreak. Since before the beginning of this disease outbreak, several COVID-19 detection and surveillance mobile applications have already been designed.

\section{TraceTogether}

This mobile application uses bluetooth signals to $\log$ when people have been close to one another. Singapore government has launched this app for contact tracing and battling

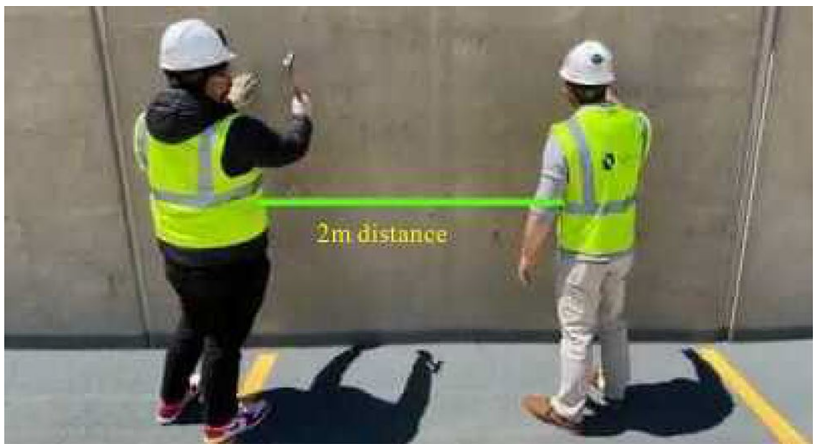

Fig. 13 Maintaining social distances using TraceTogether Apps

against the damage due to the coronavirus (Singapore 2020). TraceTogether exchanges short-distance bluetooth signals between phones to detect other participating TraceTogether users in close proximity (TraceTogether 2020a) (refer to Fig. 13). Records of such encounters are stored locally on each user's phone. These data will be used by the Ministry of Health if an individual is diagnosed with COVID-19 so that the contact tracers can aware the TraceTogether users who are close contacts of COVID-19 patient immediately to take the necessary action sooner, such as monitoring her health and following necessary measures to arrest the spreading of infection (TraceTogether 2020b).

\section{APPLE and GOOGLE Joint Contact Tracing Technology}

In this light, the GOOGLE and APPLE have initiated a joint venture to design a public contact tracing app to assist government and medical organizations across the world to their battle against COVID-19 (News 2020a). Moreover, the application enables the privacy-preserving framework. This app does not collect location information from the user's Smartphone device and without the user's consent, the data of the user will not be available to the outside world. This application follows Bluetooth technology protocol to log people's contacts by exchanging secret keys. If one of the users of this app is infected by COVID-19 and update his status in this app, an alert can be sent to others they have recently been close to, telling them that they should also get tested and/or self-isolate (News 2020b) (see Fig. 14).

\section{Voice Detection}

In the COVID-19 outbreak, by integrating AI and IoT several voice detection apps are developed for COVID-19 screening (Christian 2020). These applications need some basic demographics and medical history data along with some voice sample and analyzing the sample voice, it decides whether or not the person has symptoms of COVID-19. 


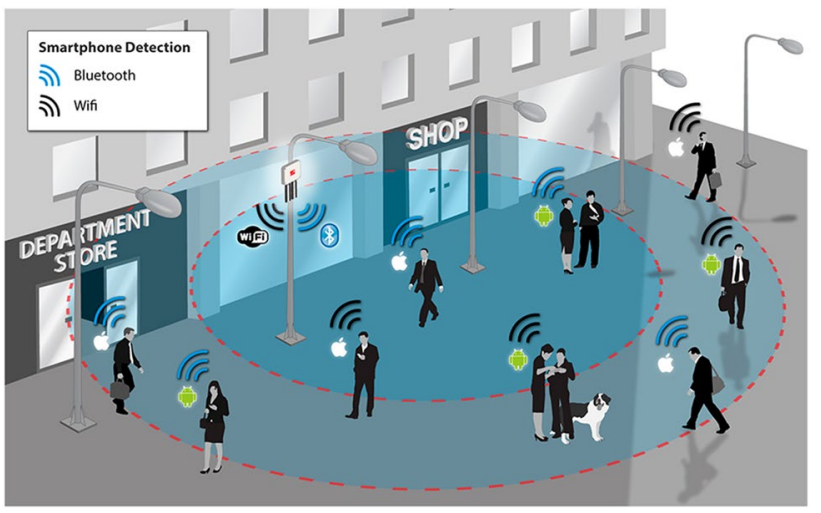

Fig. 14 Joint Google Apple contact tracing Apps for social distance maintaining and alerting system

\section{nCapp}

An intelligent diagnosis and treatment assistant for the COVID-19 pandemic (nCapp) has been proposed by China (Bai et al. 2020). The function of nCapp is to generate an automated diagnosis system in a smartphone, based on userprovided information or symptoms. The automated diagnosis system is used to confirm the suspected and suspicious cases. In the case of a confirmed patient, nCapp shows the rate of infection like mild, moderate, or severe. Moreover, this app also mentions the required treatments and precautions for all these cases. The user can update his present condition through this app so that doctor can take necessary actions accordingly.

\section{Challenges in loT-Based Infrastructure}

Several technological infrastructures have been proposed to mitigate the COVID-19 impact. Among them, IoT, AI, and Drone have been at the front-line. However, to realize the effectiveness of these emerging technologies, there is a need for high-speed internet connectivity. The excessive use of these technologies faces various challenges some of which are discussed below:

\section{Connectivity}

To recognize the efficacy of these emerging technologies high-speed internet connectivity is important. Since the implementation of the $5 \mathrm{G}$ network is still in the nascent phase, lack of infrastructure may reduce its effectiveness. Furthermore, from the installation to the maintenance of $5 \mathrm{G}$ network demand high cost, which made difficulties for the government and telecom operators to support a wide range of deployment (Huawei 2020). Another important challenge is, there are no predefined guidelines on how to collect patients' confidential data through these technologies. There may have some other security and privacy issues associated with the use of these technologies which are discussed in the next section.

\section{Privacy Issues}

In this pandemic, contact tracing technology is very useful for reducing the spread of the virus. This technology accesses and monitors the location information of users, uses the personal information of the users for providing to the government as a surveillance tool. In this situation as avoiding the use of this type of technology is impossible that's why the government has to take some responsibility to maintain the privacy of each user (McGee et al. 2020). For example, data from the user should not be made available to anyone without the user's consent and once the pandemic will be over the government should remove the user's data. The government should mention the rule of data sharing and who are accessing or monitoring the data. Accordingly, the use of drones for monitoring mass gathering and social distancing or looking for sick people in public places may hamper the privacy of people. The aerial surveillance raises serious concerns regarding the right to privacy and freedom (Safety 2020). In this pandemic, wearable devices are becoming popular in case of maintaining social distancing but there is no explanation about the use of private data collected by these devices. It is necessary to develop such wearable devices by following proper security and privacy framework.

\section{Security and Scalability Issues}

The excessive use of IoT, AI and other emerging technologies in the COVID-19 outbreak causing a serious cybersecurity problem. During this pandemic, the use of the global internet has increased 10 times more than the average (Leighton 2020). The unprecedented use of these technologies increasing malicious attacks, inserting malware to COVID-19 related apps and even user data can be hacked and misused (Davies 2020). Moreover, various organizations have started work from home (WFH) facilities and still, it is a big challenge to provide a secure digital environment to all the users. Furthermore many sectors including education, business are now becoming online which increases the possibility of cyberattacks.

In the implementation of IoT scalability is a big challenge. Multiple devices and sensor nodes are required to create a small IoT node. Due to scalability, computational power and energy constraints issues of technological devices the conventional cryptographic techniques are infeasible to implement security in these devices (Aman et al. 2017). To 
this solution, energy-efficient light-weight security algorithms are needed to provide security in IoT devices.

\section{The New Normal-Post COVID-19}

In the Post-COVID era or 'The new normal' the world is going to change in many ways and are going to look and behave very differently (Makroo 2020). From business to education, technological development will play a significant role. Almost in every possible sector including homeschooling, remote health checkup etc (Saeed et al. 2020) work from home (WFH) will be implemented with the help of digital technology. In this section, we discuss the 'post-COVID' situation and how IoT technologies can be useful to deal with the post-pandemic situation in various sectors such as health, education, economy and others.

\section{Lower Consumption}

Almost every sector is going to be accustomed to working from home (WFH) even if the lockdown opens up. In a week at least 4-5 days are involved in official work so for the middle-class people, a question could be in the mind "why do I need a wardrobe full of clothes if I can manage life with much lesser" in results overall consumerism could be decreased (Financial Express 2020).

\section{Home Schooling}

In Education from school level to universities can be imparted online and all the classes, digital libraries, laboratories will be accessed online through a smart-phone or laptop via video conferencing (Nordrum 2020) using Google classroom, Zoom apps etc (Lageard 2020). Students will go to schools, colleges once a while for group activities or for building social skills. All the important administrative meetings, technical/non-technical conferences can be organized through VR (Gent 2020) and 3D interface. The role of IoT, blue-tooth technology, robotics, AR/VR with highspeed internet connectivity surely revolutionize and provide an effective virtual educational system (Ethirajulu 2020). Moreover, it will reduce the travel expenses since all the facilities can be accessed online but high-speed internet connectivity must be provided.

\section{Uprising of loT}

During the COVID-19 pandemic situation, the IoT network has been grown amazingly and using in a wide range intelligently, in results automation in many sectors including health, education, manufacturing has been possible. The significant role of IoT amalgamation with AI, 5G internet connectivity, and other advanced technology leading to the various amazing smart applications ranges from smart ocean to smart space, smart city smart health care and smart homes (Saeed et al. 2019). This amazing revolution in the research of the IoT field will also help to ease our daily life in the post-pandemic era.

\section{Research Findings and Future Trends}

A lot of new emerging technological advancements including Machine learning, Deep learning (DL), AI, IoT, Drone and others made a great difference in mitigating the coronavirus pandemic. However, considering all these technologies, we recommend some more insights on the utilization of these technologies to fight against the COVID-19 pandemic. Researchers need to concentrate more on the development of automated and expeditious alert systems. We observe a substantial growth in IoT infrastructure amalgamated with other emerging technologies to mitigate the COVID-19 pandemic. The smartphone is also played an important role by providing various amazing applications to fight against global pandemic like COVID-19.

Data collection for COVID-19 suspected people is a crucial factor. To execute this through IoT Infrastructure requires a connection of multiple heterogeneous devices. With the increasing number of heterogeneous devices, scalability is another challenge. To manage these complex network connectivity and to support multiple functionalities, IoT network need to be designed or implemented through software define IoT. A software define network (SDN) based IoT network would be able to control the monitoring and collect data from various sources for a wide range of the area while allowing flexibility and scalability.

By analyzing huge IoT collected data, Big data analytics provides an amazing driving force in mitigating global Coronavirus pandemic (Marjani et al. 2017; Zhang et al. 2016). Several emerging technologies amalgamated with big data and AI are being proposed to fight against the pandemic, however, our realization that they fail to reach their potentiality due to the unwillingness of sharing relevant health data and personal data such as location information and others.

Further research and development might be towards improved data security, privacy, computational speed and to increase the willingness for sharing relevant data among the communities. There is a need for improvement in data sharing models. To resolve the security and privacy issues various traditional cryptographic algorithms including AES, DES, 3DES seem not suitable for IoT devices, therefore, it is required to design such energy-efficient, low computational, lightweight security algorithms to offer security, privacy in IoT devices. 
Since the number of IoT devices increasing exponentially, a high bandwidth network is desired for transmitting all the information from the sensor node to the cloud in a timely manner. At present IoT devices use a 4G/LTE network for data transmission. However, by the use of a $5 \mathrm{G}$ network this problem would be resolved.

\section{Conclusion}

While the whole world is amid a global pandemic like COVID-19, great efforts to the revolution of IoT, AI, and $5 \mathrm{G}$ are trying to alleviate its impact in an integrated way. The proposed research and methodology mainly focused on monitoring and break off the spreading of coronavirus infections. This article reviewed several emerging technologies which are adapted to fight against the COVID-19 pandemic. The adoption of IoT in context to the pandemic management was illustrated and presented in the form of a framework consisting of data collection and uploading, data analytics, healthcare professional, and healthcare or isolation center. It was realized from the research that, combat global pandemic highly depend on data collection on time. With the help of mobile applications, multiple user login is possible remotely to work in an integrated environment. Remote management can reduce physical contact among healthcare staff, professionals and patients with the help of various contact tracing technologies and apps. Covid infected and suspected people can be handled and supervised remotely and smartly with IoT-based cloud services. Apart from that, this IoT-based infrastructure has a great impact on E-learning, E-commerce and Automated industry. With the help of cloud infrastructure, people are adapted to online purchasing and contactless delivery to reduce direct contact and maintain social distances. Due to this infrastructure, it was possible to execute E-learning, where students can continue their learning through video conferencing and other learning apps. This article also highlights various designing issues that are facing by IoT-based frameworks. Moreover, several challenges including privacy, security, scalability, connectivity about pandemic management are addressed and illustrated. Finally, a few case studies are presented and discussed the post-pandemic era and the revolution of IoT and other technological transformations towards 'The New Normal'.

Funding The author(s) received no financial grant from any funding agency in the public, commercial, or not-for-profit sectors for the research, authorship, and/or publication of this article.

\section{Declarations}

Conflict of interest The authors declare that they have no conflict of interest.
Research involving human participants and/or animals This article does not contain any studies with human participants or animals performed by any of the authors.

Informed consent Informed consent was obtained from all individual participants included in the study.

\section{References}

Abdulrazaq M, Nurul I, Salah A-Z, Sairah K, Safinaz M, Eddy Y (2020) Toward a novel design for coronavirus detection and diagnosis system using IoT based drone technology. Int J Psychosoc Rehabil 24:2287-2295. https://doi.org/10.37200/IJPR/ V24I7/PR270220

Ackerman E (2017) Facedisplay and other bizarre virtual reality projects from chi 2017 [Online]. https://spectrum.ieee.org/ tech-talk/consumer-electronics/audiovideo/facedisplay-andother-bizarre-virtual-reality-projects-from-chi-2017. Accessed 10 May 2017

Afelt A, Frutos R, Devaux C (2018) Bats, coronaviruses, and deforestation: toward the emergence of novel infectious diseases? Front Microbiol 9:702

Allam Z, Jones DS (2020) On the coronavirus (COVID-19) outbreak and the smart city network: universal data sharing standards coupled with artificial intelligence (AI) to benefit urban health monitoring and management. Healthcare (Basel) 8(1)

Aman MN, Chua KC, Sikdar B (2017) Secure data provenance for the internet of things. In: Proceedings of the 3rd ACM international workshop on IoT privacy, trust, and security, pp 11-14

Amazon (2020) Amazon has hired 175,000 additional people [online]. https://blog.aboutamazon.com/company-news/amazon-hiringfor-additional-75-000-jobs. Accessed May 2020

Atkeson A (2020) What will be the economic impact of COVID-19 in the US? Rough estimates of disease scenarios, Tech. rep., National Bureau of Economic Research

Azimi I, Anzanpour A, Rahmani AM, Paikkala T, Levorato M, Liljeberg P (2017) HICH: hierarchical fog-assisted computing architecture for healthcare IoT. ACM Trans Embed Comput Syst (TECS) 16(5s): 174

Backer AJ, Klinkenberg D, Wallinga J (2020) Incubation period of 2019 novel coronavirus (2019-nCoV) infections among travelers from Wuhan. Euro Surveill. https://doi.org/10.2807/1560-7917. ES.2020.25.5.2000062

Bahuguna Y, Verma A, Raj K (2018) Smart learning based on augmented reality with android platform and its applicability. In: 2018 3rd International conference on internet of things: smart innovation and usages (IoT-SIU), pp 1-5

Bai L, Yang D, Wang X, Tong L, Zhu X, Zhong N, Bai C, Powell CA, Chen R, Zhou J, Song Y, Zhou X (March 2020) Chinese experts' consensus on the internet of things-aided diagnosis and treatment of coronavirus disease 2019. Clin eHealth 6(111). https://doi.org/ 10.1016/j.ceh.2020.03.001

Bassam N, Asif H, Qaraghuli A, Khan J, Sumesh E, Lavanya V (2021) IoT based wearable device to monitor the signs of quarantined remote patients of COVID-19. Inform Med Unlocked 24:100588. https://doi.org/10.1016/j.imu.2021.100588

Blog G (2020) Privacy-safe contact tracing using bluetooth low energy [online]. https://blog.google/documents/57/Overviewof-COVID-19-Contact-Tracing-Using-BLE.pdf

Bluetooth (2020) Fighting against COVID-19 via privacy-first bluetooth tracing [online]. https://github.com/covid19cz/erouskaandroid. Accessed 06 June 2020 
Cascella ACSCDM, Rajnik M, Napoli RD (2020) Features, evaluation and treatment coronavirus (COVID-19) [updated 2020 Apr 6] in StatPearls [Internet]. StatPearls Publishing, Treasure Island

Chai PR, Zhang H, Baugh CW, Jambaulikar GD, McCabe JC, Gorman JM, Boyer EW, Landman A (2018) Internet of things buttons for real-time notifications in hospital operations: proposal for hospital implementation. J Med Internet Res 20(8):e251. https:// doi.org/10.2196/jmir.9454

Chakraborty I, Maity P (2020) COVID-19 outbreak: migration, effects on society, global environment and prevention. Sci Total Environ 728. https://doi.org/10.1016/j.scitotenv.2020.138882. https://linki nghub.elsevier.com/retrieve/pii/S0048969720323998

Chamola V, Hassija V, Gupta V, Guizani M (2020) A comprehensive review of the COVID-19 pandemic and the role of IoT, drones, $\mathrm{AI}$, blockchain, and $5 \mathrm{~g}$ in managing its impact. IEEE Access 8:90225-90265

Charters L (2020) COVID-19: smart thermometer shows real-time changes in fever levels [online]. https://www.ophthalmologyti mes.com/view/covid-19-smart-thermometer-shows-real-timechanges-in-fever-levels. Accessed 11 July 2020

Choudhary M (2020) How IoT can help fight COVID-19 battle [online]. https://www.geospatialworld.net/blogs/how-iot-canhelp-fight-covid-19-battle/. Accessed May 2020

Chowdhury MT, Sarkar A, Paul SK, Moktadir MA (2020) A case study on strategies to deal with the impacts of COVID-19 pandemic in the food and beverage industry. Oper Manag Res. https://doi. org/10.1007/s12063-020-00166-9

Chowdhury P, Paul SK, Kaisar S, Moktadir MA (2021) COVID-19 pandemic related supply chain studies: a systematic review. Transp Res Part E Logist Transp Rev 148:102271. https://doi. org/10.1016/j.tre.2021.102271. https://www.sciencedirect.com/ science/article/pii/S1366554521000478

Christian J (2020) New app attempts to detect signs of COVID-19 using voice analysis [online]. https://futurism.com/neoscope/ new-app-detects-covid19-voice. Accessed 31 Mar 2020

Davies N (2020) Are we ready for a post-covid-19 cyberse curity landscape? [online]. http://www.circleid.com/posts/20200501are-we-ready-for-a-post-covid-19-cybersecurity-landscape/. Accessed 03 May 2020

de Sousa Jabbour ABL, Jabbour CJC, Hingley M, Vilalta-Perdomo EL, Ramsden G, Twigg D (2020) Sustainability of supply chains in the wake of the coronavirus (COVID-19/SARS-CoV-2) pandemic: lessons and trends. Modern Supply Chain Res Appl 2(3):117-122. https://doi.org/10.1108/MSCRA-05-2020-0011

Decker K (2020) ESRI partners respond to COVID-19 with location intelligence offerings. https://www.esri.com/arcgis-blog/produ cts/arcgis/health/esri-partners-respond-to-covid-19-with-mappi ng-and-locationintelligence-offerings/

Dudhe PV, Kadam NV, Hushangabade RM, Deshmukh MS (2017) Internet of things (IoT): an overview and its applications. In: 2017 International conference on energy, communication, data analytics and soft computing (ICECDS), pp 2650-2653

Ethirajulu B (2020) How 5g and edge computing can enhance virtual reality [online]. https://www.ericsson.com/en/blog/2020/4/how$5 \mathrm{~g}$-and-edge-computing-can-enhance-virtual-reality. Accessed 28 Apr 2020

Financial Express (2020) What will be the "new normal" post covid-19 [online]. https://www.financialexpress.com/brandwagon/whatwill-be-the-new-normal-post-covid-19/1961789/. Accessed 1st Aug 2020

Froilan M (2020) Using learning management systems in an internet of things (IoT) smartwatch device amidst COVID-19 crisis. In: International conference on COVID-19 studies

Gallagher P, Kring WR, Ocampo JA (2020) Calibrating the COVID19 crisis response to the SDGS. https://www.un.org/en/un-coron avirus-communications-team/calibrating-covid-19-crisis-respo nse-sdgs

Gent E (2020) Forget video conferencingâĂŤhost your next meeting in vr [Online]. https://spectrum.ieee.org/tech-talk/consumer-elect ronics/audiovideo/forget-video-conferencinghost-your-nextmeeting-in-vr. Accessed 21 Apr 2020

Goodman D (2020) World economy faces $\$ \$ 5$ trillion hit that's like losing Japan. Bloombergquint [online]. https://www.bloombergq uint.com/global-economics/world-economy-faces-5-trillion-hitthat-is-like-losing-japan. Accessed Apr 2020

Goswami SA, Padhya BP, Patel KD (2019) Internet of things: applications, challenges and research issues. In: 2019 Third international conference on I-SMAC (IoT in Social, Mobile, Analytics and Cloud) (I-SMAC), pp 47-50

Haleem A, Javaid M, Vaishya R (2020) Effects of COVID 19 pandemic in daily life. Curr Med Res Pract. https://doi.org/10.1016/j.cmrp. 2020.03 .011

Hao K (2020) Over 24,000 coronavirus research papers are now available in one place. https://www.technologyreview.com/2020/03/16/ 905290/coronavirus-24000-research-papers-available-open-data/

Hassan MU, Rehmani MH, Chen J (2019) Privacy preservation in blockchain based IoT systems: integration issues, prospects, challenges, and future research directions. Future Gener Comput Syst 97:512-529. https://doi.org/10.1016/j.future.2019.02.060

Heikkila A (2017) Wearable technology in elearning: 3 wearables that have the most potential [online]. https://elearningindustry.com/ wearable-technology-in-elearning-3-wearables-potential

$\mathrm{Hu}$ F, Xie D, Shen S (2013) On the application of the internet of things in the field of medical and health care. In: Proceedings IEEE international conference on green computing and communications and IEEE internet of things and IEEE cyber, physical and social computing

Huawei D (2020) Combating COVID-19 with 5g: opportunities to improve public health systems [online]. https://www-file.huawei. com/-/media/corporate/local-site/ua/pdf/deloitte-cn-consulting5g-assist-in-2019-ncov-en-200317.pdf?la=uk-ua. Accessed 27 Apr 2020

Javaid M, Haleem A, Vaishya R, Bahl, Suman R, Vaish A (2020a) Industry 4.0 technologies and their applications in fighting COVID-19 pandemic. J Diabetes Metab Syndr 14(4):419-422. https://doi.org/10.1016/j.dsx.2020.04.032

Javaid M, Haleem A, Vaishya R, Kan IH (2020b) Artificial intelligence (AI) applications for COVID-19 pandemic. J Diabetes Metab Syndr 14(4):337-339. https://doi.org/10.1016/j.dsx.2020.04.012

Jorge MCH, da Costa CA, da Rosa Righi R, Stoffel AR (2020) Fog computing in health: a systematic literature review. Health and Technology. Springer. https://doi.org/10.1007/ s12553-020-00431-8

Karmaker CL, Ahmed T, Ahmed S, Ali SM, Moktadir MA, Kabir G (2021) Improving supply chain sustainability in the context of COVID-19 pandemic in an emerging economy: exploring drivers using an integrated model. Sustain Prod Consum 26:411-427. https://doi.org/10.1016/j.spc.2020.09.019. https://www.scien cedirect.com/science/article/pii/S2352550920308794

Kaur A (2020) How aarogya setu app works and how it helps fight COVID [Online]. https://www.livemint.com/ai/artificial-intel ligence/how-aarogya-setu-app-works-and-how-it-helps-fightcovid-11594512597402.html. Accessed 12 July 2020

Keyes D (2019) Kaust launches vfablab ${ }^{\mathrm{TM}}$, its first virtual lab [online]. https://www.kaust.edu.sa/en/news/kaust-launches-vfablabE28 4A2-its-first-virtual-lab. Accessed Apr 2019

Khaddar MAE, Boulmalf M (2017) Smartphone: the ultimate IoT and IoE device, smartphones from an applied research perspective. https://www.intechopen.com/books/smartphonesfrom-an-applied-research-perspective/smartphone-the-ultim ate-iot-and-ioe-device" 
Khan W, ur Rehman MH, Zangoti H, Afzal M, Armi N, Salah K (2019) Industrial internet of things: recent advances, enabling technologies, and open challenges. Comput Electr Eng 81. https://doi.org/10.1016/j.compeleceng.2019.106522

Kshetri N (2018) 5g in e-commerce activities. IT Prof 4:73-77

Kumar M, Nayar N, Mehta G, Sharma A (2021) Application of IoT in current pandemic of COVID-19. IOP Conf Ser Mater Sci Eng 1022:012063. https://doi.org/10.1088/1757-899x/1022/1/ 012063

Kumari M, Kumar A, Singhal R (2020) Design and analysis of IoTbased intelligent robot for real-time monitoring and control. In: 2020 International conference on power electronics IoT applications in renewable energy and its control (PARC), pp $549-552$

Lageard J (2020) How technology can combat covid-19? [online]. https://www.techuk.org/insights/opinions/item/17314-guestblog-how-technology-can-combat-covid-19. Accessed $20 \mathrm{Apr}$ 2020

Leighton T (2020) Can the internet keep up with the surge in demand? [online]. https://blogs.akamai.com/2020/04/can-the-internetkeep-up-with-the-surge-in-demand.html. Accessed 10 May 2020

Lokhman MT, Rasam AR Abdul, Noor AMM (2012) Reforming health care facility using geographical information system. In: 2012 IEEE control and system graduate research colloquium, pp 267-270

Makroo S (2020) Technology and business order post covid-19 [online]. https://www.orfonline.org/expert-speak/technologyand-business-order-post-covid-19-64471/. Accessed May 2020

Malliga S, Kogilavani SV, Nandhini PS (2021) A comprehensive review of applications of internet of things for COVID-19 pandemic. IOP Conf Ser Mater Sci Eng 1055(1):012083. https://doi. org/10.1088/1757-899x/1055/1/012083

Marjani M, Nasaruddin F, Gani A, Karim A, Hashem IAT, Siddiqa A, Yaqoob I (2017) Big IoT data analytics: architecture, opportunities, and open research challenges. IEEE Access, pp 5247-5261

Marr B (2020a) 9 future predictions for a post-coronavirus world [online]. https://www.forbes.com/sites/bernardmarr/2020/04/ 03/9-future-predictions-for-a-post-coronavirus-world/92698 4d54106. Accessed 20 Apr 2020

Marr B (2020b) Robots and drones are now used to fight COVID-19, Tech. rep., Forbes

McGee P, Murphy H, Bradshaw T (2020) Coronavirus apps: the risk of slipping into a surveillance state [online]. https://www.ft.com/ content/d2609e26-8875-11ea-a01c-a28a3e3fbd33. Accessed 10 May 2020

Mondal S, Ghosh I, Gupta A, Ghosh S, Basu D (2021) Role of the internet of things for early detection of COVID-19 infections: a comprehensive survey. In: 2nd International conference on IoT based control networks and intelligent systems (ICICNIS 2021), pp 1-8

Nasajpour M, Pouriyeh S, Parizi RM, Dorodchi M, Valero M, Arabnia HR (2020a) Internet of things for current COVID-19 and future pandemics: an exploratory study. J Healthc Inform Res 4(4):325364. https://doi.org/10.1007/s41666-020-00080-6

Nasajpour M, Pouriyeh S, Parizi RM, Dorodchi M, Valero M, Arabnia HR (2020b) Internet of things for current COVID-19 and future pandemics: an exploratory study. arXiv:2007.11147v1 [cs.CY]

News A (2020b) Privacy-preserving contact tracing — apple and google. https://www.apple.com/ covid19/contacttracing/

News G (2020) Apple and google partner on COVID-19 contact tracing technology [online]. https://blog.google/inside-google/compa nyannouncements/apple-and-google-partner-covid-19-contacttracingtechnology. Accessed Apr 2020

Nordrum A (2020) At\&t feud with freeconferencecall.com heats up [online]. https://spectrum.ieee.org/tech-talk/telecom/wireless/ att-feud-freeconferencecallcom-heats-up. Accessed 21 Apr 2020
Nosta J (2020) GPS tracking in the era of COVID-19 [online]. https://www.psychologytoday.com/us/blog/the-digital-self/ 202004/gps-tracking-in-the-era-covid-19. Accessed 06 Apr 2020

Octopus (2020) Octopus national health crisis management platform and quarantine monitoring app. https://octopus-app.com/perso nal-safety-app/. Accessed Aug 2020

Oyeniyi J, Kazeem I, Oyeniran O, Omotosho L (2020) Application of internet of things (IoT) to enhance the fight against COVID-19 pandemic, vol 1, pp 38-42

Panarello A, Tapas N, Merlino G, Longo F, Puliafito A (2018) Blockchain and IoT integration: a systematic survey. Sensors 18:2575. https://doi.org/10.3390/s18082575

Pratama AYN, Zainudin A, Yuliana M (2017) Implementation of IoTbased passengers monitoring for smart school application. In: 2017 International electronics symposium on engineering technology and applications (IES-ETA), pp 33-38

Qi J, Yang P, Min G, Amft O, Dong F, Xu L (2017) A comprehensive review of the COVID-19 pandemic and the role of IoT, drones, AI, blockchain, and $5 \mathrm{~g}$ in managing its impact. Pervasive Mob Comput 41:132-149

Qualcomm (2020) What is 5g: Everything you need to know about $5 \mathrm{~g}: 5 \mathrm{~g}$ faq [online]. https://www.qualcomm.com/invention/5g/ what-is-5g. Accessed 6th April 2020

Rahman MS, Peeri NC, Shrestha N, Zaki R, Haque U, Hamidd SHA (2020) Defending against the novel coronavirus (COVID-19) outbreak: how can the internet of things (IoT) help to save the world? Health Policy Technol (Elsevier) 9((2)):136-138. https:// doi.org/10.1016/j.hlpt.2020.04.005

Reddy M, Krishnamohan R (2017) Applications of IoT: a study. Int J Trend Res Dev. https://doi.org/10.13140/RG.2.2.27960.60169

Richardson M (2020) Pandemic drones: Useful for enforcing social distancing or for creating a police state?. https://gcn.com/artic les/2020/03/31/pandemic-drones.aspx

Sachin K, Prayag T, Mikhail Z (2019) Internet of things is a revolutionary approach for future technology enhancement: a review. J Big Data 6(111). https://doi.org/10.1186/s40537-019-0268-2

Saeed N, Alouini MS, Al-Naffouri TY (2019) Towards the internet of $\mathrm{x}$-things: new possibilities for underwater, underground, and outer space exploration 2019

Saeed N, Bader A, Alouini M (2020) When wireless communication faces COVID-19: combating the pandemic and saving the economy. arXiv:2005.06637v2 [cs.CY]

Safety (2020) Safety or surveillance: drones and the covid-19 pandemic [online]. https://www.marketplace.org/shows/marketplace-tech/ covid-19-pandemic-drones-safety-surveillance/. Accessed 10 May 2020

Schmitt M (2020) How to fight COVID-19 with machine learning [online]. https://www.datarevenue.com/en-blog/machine-learn ing-covid-19. Accessed Aug 2020

Shahed KS, Azeem A, Ali SM, Moktadir MA (2021) A supply chain disruption risk mitigation model to manage COVID-19 pandemic risk. Environ Sci Pollut Res. https://doi.org/10.1007/ s11356-020-12289-4

Sharma M (2020) How drones are being used to combat COVID-19 [online]. https://www.geospatialworld.net/blogs/how-drones-arebeing-used-to-combat-covid-19/. Accessed 20 Apr 2020

Shaw KK, Vimalkumar R (2020) Design and development of a drone for spraying pesticides, fertilizers and disinfectants. Int J Eng Res Technol 09(05)

Singapore G (2020) Tracetogether-behind the scenes look at its development process [online]. https://www.tech.gov.sg/media/techn ews/tracetogether-behind-the-scenes-look-at-its-developmentprocess. Accessed March 2020

Singh R Pratap, Javaid M, Haleem A, Vaishya R, Ali S (2020a) Internet of medical things (IOMT) for orthopaedic in COVID-19 
pandemic: roles, challenges, and applications. J Clin Orthop Trauma 11(4):713-717. https://doi.org/10.1016/j.jcot.2020.05. 011

Singh RP, javid M, Haleem A, Suman R (2020b) Internet of things (IoT) applications to fight against COVID-19 pandemic. J Diabetes Metab Syndr 14(4):521-524. https://doi.org/10.1016/j.dsx. 2020.04.041

Sisinni E, Saifullah A, Han S, Jennehag U, Gidlund M (2018) Industrial internet of things: challenges, opportunities, and directions. IEEE Trans Ind Inform 14(11):4724-4734

Suroor N, Khan S (2017) COVID-19 crisis and digital learning: need to revamp education system [online]. https://government.econo mictimes.indiatimes.com. Accessed 27 Apr 2020

Swayamsiddhaa S, Mohanty C (2020) Application of cognitive internet of medical things for COVID-19 pandemic. J Diabetes Metab Syndr 14((5)):911-915. https://doi.org/10.1016/j.dsx.2020.06. 014

Tahmid R, Dong W (2020) Covidsens: a vision on reliable social sensing for COVID-19. Artif Intell Rev. https://doi.org/10.1007/ s10462-020-09852-3

Tang H, Shi J, Lei K (2016) A smart low-consumption IoT framework for location tracking and its real application. In: 2016 6th International conference on electronics information and emergency communication (ICEIEC), pp 306-309

Tavakoli M, Carriere J, Torabi A (05 2020) Robotics, smart wearable technologies, and autonomous intelligent systems for healthcare during the COVID-19 pandemic: an analysis of the state of the art and future vision. Adv Intell Syst 2. https://doi.org/10.1002/ aisy.202000071

Thomas Z (2020) Coronavirus: will COVID-19 speed up the use of robots to replace human workers?, Tech. rep., BBC News

Ting DSW, Carin L, Dzau V, Wong TY (2020) Digital technology and COVID-19. Nat Med 26:459-461. https://doi.org/10.1038/ s41591-020-0824-5

Trace P (2020) In the time of COVID-19 âĂŞ how will you maintain safe working distances? [online]. https://www.triaxtec.com/resou rce/fact-sheet/proximity-trace/. Accessed 21 Apr 2020

TraceTogether (2020a) Tracetogether, safer together [online]. https:// www.tracetogether.gov.sg/. Accessed 06 June 2020

TraceTogether (2020b) Help speed up contact tracing with tracetogether [online]. https://www.gov.sg/article/help-speed-up-conta ct-tracing-with-tracetogether. Accessed 19 June 2020
Uraguchi T, Omiya Y, Takano T, Amemiya Y, Nakamura M, Takayama E, Tokuno S, Deguchi H (2019) Evaluation of smart devices in the IoT segment using medical healthcare technology MIMOSYS. In: 2019 12th Asian control conference (ASCC), pp 91-96

Whiteside P (2020) Coronavirus lockdowns unlocked: which countries are easing restrictions. https://news.sky.com/story/coron avirus-lockdowns-unlocked-which-countries-are-easing-restr ictions-11974027

WHO (2020a) Coronavirus disease (COVID-19) advice for the public, Tech. rep., World Health Organization

WHO (2020b) Coronavirus disease (COVID-19) pandemic, Tech. rep., World Health Organization

World Bank (2020) The economy in the time of COVID-19., Tech. rep. https://openknowledge.worldbank.org/handle/10986/33555. Accessed 20 Apr 2020

Xiaosheng L, Yuxuan L (2009) The research about city safety information system based on GIS. In: 2009 International forum on computer science-technology and applications, vol 3, pp 100-103

Young R, McMahon S (2020) Kinsa smart thermometer data predicts new COVID-19 spikes weeks before CDC [Online]. https://www. wbur.org/hereandnow/2020/06/25/covid-19-kinsa-smart-therm ometer. Accessed 25 June 2020

Yusuf P, Kashiful H, Firoj P, Mumdouh M (2019) The internet of things (IoT) and its application domains. Int J Comput Appl 182:36-49. https://doi.org/10.5120/ijca2019918763

Zema N, Natalizio E, Ruggeri G, Poss M, Molinaro A (2016) Medrone: on the use of a medical drone to heal a sensor network infected by a malicious epidemic. Ad Hoc Netw 50. https://doi.org/10. 1016/j.adhoc.2016.06.008

Zhang Y, Zhang L, Oki E, Chawla NV, Kos A (2016) IEEE access special section editorial: big data analytics for smart and connected health. IEEE Access 4:9906-9909

Zhu N, Zhang D, Wang W (2020) A novel coronavirus from patients with pneumonia in china. N Engl J Med 382(8):727-733. https:// doi.org/10.1056/NEJMoa2001017

Publisher's Note Springer Nature remains neutral with regard to jurisdictional claims in published maps and institutional affiliations. 